\title{
Gross and Histopathological Lesion Induced on the Gills Ofbarbus Fish by Monogenea Trematods Habiteting in Western Part of Lake Tana, Amhara Region, Ethiopia
}

\author{
Abiyot Workeale \\ takusa district livestock development office \\ samrawit melkamu ( $\nabla$ samrawit.m2129@gmail.com ) \\ samara university, afar
}

\section{Research Article}

Keywords: Barbus fish, histopathology, Lake Tana, monogenea, pathology

Posted Date: September 7th, 2021

DOI: https://doi.org/10.21203/rs.3.rs-832497/v1

License: (c) (i) This work is licensed under a Creative Commons Attribution 4.0 International License. Read Full License 


\section{Abstract}

Back ground: Gill parasitic is common on cultured and wild fish. Many of these species have long been recognized to have the potential to affect the growth, fecundity and survival of hosts.the objective of the study were to determine the prevalence and identify, gross and histopathological lesion of gills caused by Dactylogyrus and Gryodactylus spp. parasitic infection on naturally infected barbus fish.

Result: A cross sectional study was conducted from in Lake Tana, amhara region. Three hundred eight four gill specimens were collected from barbus fish and of these, $22(5.7 \%)$ of fish were infected with monogenean parasites. Higher prevalence of Dactylogyrus spp. (4.86\%) was recorded than Gryodactylus sp (1.04). Large size fishes ( $\geq 20 \mathrm{~cm}$ ) were more susceptible to Dactylogyrus spp and Gryodactylus spp. However, highest prevalence of Dactylogyrus sp. was found in large fish size (6.85\%). Gryodactylus sp. was not recorded in all small size fish. Descriptive statistics such as percentages was used to describe the nature and the characteristics of the disease. At gross examination of gills, hyperaemia and swollen, excess mucus secretion, paleness, congestion of branchial blood vessel were observed. Gills specimens of infected fish were fixed with $10 \%$ formalin, for further identification and stained with the haematoxylineosin. Histopathological changes included hyperplasia, congestion and mucous cell proliferation of the gill epithelium and damaged primary and secondary lamellae, the uplifting of respiratory epithelial wall and damaged pillar cells.

Conclusion: Gross and histopathological changes induced by the Dactylogyrus spp and Gryodactylus spp of parasites adversely affected the proper functioning of the gills of the host fish which can lead to detrimental effect on the health status of the fish and may result in huge economic losses through increased mortality.

\section{Background}

Gill parasites are common on cultured and wild fish. Many of these species have long been recognized to have the potential to affect the growth, fecundity and survival of hosts [1] Moreover, extensive tissue damage resulting from the feeding and attachment of these parasites have been reported in several species of fish [2]. Among the comment fish parasite, Dactylogyrus sp. was mostly observed in gills. Dactylogyrus sp have a series of hooks that enable them to attach while feeding. Most species are hostand site-specific, requiring only one host to complete an entire life cycle. Fish parasites result in huge economic losses as they increase mortality and also increase farm inputs via increased treatment expenses and cause reduction in growth rate due to the parasitic disease outbreak [3].

Also there was no research work conducted on gross and histopathological analysis on lesions caused by monogenea parasite of barbus fish at Lake Tana. Therefore, the objectives of this study were: General objective: The general aim of the study was to determine the pathological effect of gill trematode infection and the prevalence of gill Dactylogyrus spp and Gryodactylus spp of barbus fish at western part of the Lake Tana, Amahara region. Specific objectives: To determine the prevalence of gill 
Dactylogyrus spp and Gryodactylus spp parasites in barbus fish in western part of LakeTana, to identify the type of Dactylogyrus spp and Gryodactylus spp parasites affecting gills on barbus fish in western part of Lake Tana and to determine the gross and histopathological lesions caused by the identified parasite of gills in barbus fish at western part of Lake Tana.

\section{Results}

A total number of 384 laebo barbus fish were observed in Lake Tana. Out of the 384 fish examined, 22 (5.72) were infested with monogenean parasites where the prevalence of Dactylogyrus sp. was $4.86 \%$ while that of Gyrodactylus sp. was 1.04\% (Table 1).

Table 1

Prevalence of Gyrodactylus sp and Dactylogyrus sp in barbus fish in the study site.

\begin{tabular}{|lllll|}
\hline Parasite species & No. examined & No. Infected & $X^{2}$ & P-value \\
Gyrodactylus & 384 & 4 & 9.17 & 0.0025 \\
Dactylogyrus & 384 & 18 & & \\
Total & 384 & 22 & & \\
\hline
\end{tabular}

Highest prevalence of Dactylogyrus sp. was found in large sized fish group (6.85\%) and lowest in small sized fish group (2.29\%). While highest prevalence of Gyrodactylus sp. was observed in large fish group $(1.717 \%)$ and lowest in medium sized fish group $(0.81 \%)$. Gyrodactylus sp. infestation was not recorded in small sized fish group.

Table 2

Length wise prevalence (\%) of Dactylogyrus and Gryodactylus sp. in the study area

\begin{tabular}{|llll|}
\hline Body length $(\mathrm{cm})$ & No. examined & Dactylogyrus sp & Gyrodactilus sp. \\
\hline Small (1-10) & 87 & $2(2.38)$ & - \\
\hline Medium (10.5-20) & 122 & $4(3.27)$ & $1(0.81)$ \\
\hline Large $(>20)$ & 175 & $12(6.85)$ & $3(1.71)$ \\
\hline Total & 384 & 18 & $4(1.04)$ \\
\hline
\end{tabular}

\section{Gross lesion examination}

Gross examination of gill tissues caused by monogenean parasite revealed pale gills ( 22 infected fish), excess mucus production (8 infected fish), hyperemic ( 2 infected fish) and swollen gill tissue (18 infected 
fish), hemorrhage (1 infected fish), congestion of (1 infected fish) was observed.

\section{Histopathological lesions}

Microscopic pathological changes were observed on the gills of parasitized fish, and they were comprised of fusion, curling and necrotic change the gill filaments. The proliferation of bronchial tips, atrophy, complete loss of gill lamellar epithelium, hyperplasia and fusion of secondary gill lamellae were recorded. Uplifting of primary and secondary gill lamellae epithelium was also observed. Leucocytes infiltration, telangiectasia in secondary lamellae, congestion on the gill filaments and mucous cells proliferation were also observed during hitopathological examination.

\section{Discussions}

In present study, the histopathological effect caused by monogenea is mainly due to their morphological structures and specialized mode of attachment with host tissues. Infestation of the fish with Gryodactylus and Dactylogyrus, resultes severe damage to gills lamellae may be similar to lesions that were reported by [4].

In this study the Parasites attach gill epithelium and destruction of the cells or by congesting blood from the ruptured blood vessels. Gill epithelial cells are mechanically injured by the hooks of identified parasites. The blood expelled from this would be fed by the parasite and activity of some parasites can lead to bacterial or fungal secondary infection and causes mass mortality in cultured and wild situation and consequently fish respiration will be impaired, which results in reduced feeding, weight loss and general deterioration of health. Decreasing the body weight and condition factor, sever changes in osmoregulation or respiratory dysfunction and finally death may be observed in infection with Gryodactylus and Dactylogyrus parasite these study agree with [5].

The histopathological lesion which is observed in this study include lamellar fusion, hyperplasia, and aneurysm. Some alternations in blood vessel may occur when fish suffer from severe types of stress. In this case, damaged pillar cells can result in an increased blood flow inside the lamellae and cause blood congestion or even an aneurysm [6]. In the present study of monogenea infection, gill inflammation, swollen, hyperemic, hemorrhage, and excessive mucus production were recorded in infected barbus fish gill tissue. Leads to, blockage of blood vessels leading to respiratory and osmoregulatory failure according to [7].

In the present study, necrosis lamellae were observed in barbus fish infected with Gryodactylus and Dactylogyrus spp of monogenean parasites. The mechanism by which the destruction of the branchial vessels may happen by the parasite, where the blood pressure is low and no extensive hemorrhages are caused and the very short clotting time of blood brings about rapid occlusions of the vessel then thrombus is formed resulting in ischemia, which in turn leads to necrosis, these result similar with [8] and [9]. In the present study, reduced chloride cells were seen. The infection of identified parasite in fish 
gills has an impact on the host's ability to regulate its ion balance. These findings agree with reports of [10] and [11]. These parasites reduced the number of chloride cells which are the main site of ion absorption and secretion [12].

In the present study heamorrhage was observed. Gryodactylus and Dactylogyrus parasitic damage the gills by feeding on the delicate tissue of the gill lamellae or on the blood circulating within the lamellae, leading to a loss of respiratory surface area, extensive gill damage and severe hemorrhage, with inflammation. Blood vessels in the gill filaments are blocked and this leads to atrophy of gill tips .these findings is agree with [13]and [14].

\section{Conclusions}

The major features of Gryodactylus and Dactylogyrus parasite spp. infections on the gill filaments of the fish in this study mostly include destruction of the gill filaments and lamellae, exerted by feeding of the parasite and the result in hyperplasia and thickening of the epithelial cells reducing the surface area for effective respiration. Gill damage could result in loss of gill surface area for respiration, which would lead to suffocation particularly at high water temperatures. The histoarchitectural change in gills hinders the oxygen intakes and in the long term causes huge mortality in aquaculture practices. According to the result of the gross and histopathological changes induced by the infections of parasites would adversely affect the proper functioning of the gills of infected fish. Further study should be warranted on the prevalence and effect of other parasites.

\section{Materials And Methods Study population}

The study animals were fish of barbus (Labeo barbus) that was collected from Lake Tana, Amahara region, Ethiopia. Sampled fishes were selected by simple random sampling technique. Large, medium and small sized fishes were included in my study. Large, medium and small sized fishes were selected by simple random sampling techniques associations that are found in western part of Lake Tana. The study population, small $(1$ to $10 \mathrm{~cm})$, medium $(10.5$ to $20 \mathrm{~cm})$ and large size fishes $(\geq 20 \mathrm{~cm})$ were categorized according to [15].

\section{Sample collection techniques, gross and histopathological examination}

A total of 384 randomly selected fish, Labeo barbus, were sampled and examined. The length, date and site of collection of host specimens were recorded. Gross lesion and health conditions of each specimen were recorded and monogenean parasite (Gryodactylus and Dactylogyrus ssp.) of gills were collected with forceps. Postmortem examination of gills of the investigated fishes was examined according to 
[16]. Damaged fish tissues (gills) were taken from the parasite attachment area of infested fishes and were cut out in fresh condition fixed in $10 \%$ buffered neutral formalin. In addition, monogeneans parasites of gills were collected and preserved $10 \%$ buffered neutral formalin. Then, the necessary information were leveled on the sampling bottles. Finally, the samples were transported to Faculty of Veterinary Medicine Pathology and parasitology laboratory, University of Gondar, for identification of parasites and histopathological examination of tissue specimens. After used the fixative, the tissue were washed in running water for $24 \mathrm{hr}$ to remove the fixative entirely. The tissues were then processed using a $18 \mathrm{hr}$ automatic tissue processor. The tissue processor contains 12 beakers ( 8 glass beakers contains alcohol, 2 glass beakers contains xylene and 2 glass beakers containing paraffin wax).

The tissues after being processed are embedded using an automatic embedding centre. Embedding is a process of submerging a tissue in a metal plastic disposable embedding mould containing molten paraffin wax, which became solidified when it was cold. This formed a support medium for the tissue during sectioning. The blocked tissues were sectioned at 4-5 microns a rotary microtome (LEITZ 2535, Germany), and floated into pre coated slides and were placed in a clean grease free slide which was then placed on a hot plate for $30 \mathrm{~min}$ in order for section to adhere to the slides. The staining method used was the H\&E staining method. Standard histological procedure was followed as described by [17]. This method was used in order to demonstrate the general structure of the tissues. These were then dewaxed in xylene. The processed section were later taken to water by using descending grades of alcohol, that is, from absolute alcohol, $95 \%$ alcohol, $70 \%$ alcohol,50 \%,for 5 min each and rinse tap water for $10 \mathrm{~min}$. It was stained in haematoxylin for 6 min, then put in running water for 20 min.

This was counter stained in $1 \%$ Eosin for 15 min and, then dehydrated using ascending grades of alcohol (95\% alcohol and absolute alcohol). These were cleared in xylen, mounted using D.P.X (a mountant) and viewed under light microscope [18]. Lesions were described and scored as none for no lesion, mild, or severe depends on the type of lesion [19]. Preserved in $10 \%$ formaline and labeled with all necessary information for further identification. The collected parasites placed on glass micro-scope slides with a drop of $10 \%$ formalin and slightly compressed between a slide and a cover slip prior to being examined under stereomicroscope $(4 x, 10 x .40 x)$ and observe morphological feature of the parasite. The monogeneas parasites were identified microscopically using the identification guideline of [20].

\section{Data analysis}

The data were entered and managed in Microsoft Excel. All the data analysis was done by SPSS software version 12. Descriptive statistics was applied for the analysis of the data obtained. Descriptive statistics such as percentages were used to describe the nature and the characteristics of the data. The prevalence of monogenea parasite (Gryodactylus and Dactylogyrus spp.) was analyzed using Chi-square test and $<0.05$ was considered as significant.

\section{Declarations}




\section{Acknowledgements}

The authors would like to extend their thanks to: Gondar University for free support to conduct histopathology tasks.

\section{Author's contribution}

Samrawit Melkamu-Mekonnon contributed for data collection, sample analysis, data summarization manuscript preparation Abiyot Workeale Alemu, for manuscript preparation, data analysis; statistical analysis, table and figure preparation as a contribution.

\section{Funding}

This research is self funding, histopathological process freely supported by Gondar university.

\section{Availability of data and materials}

All data supporting these research findings are included within the manuscript. The databases (without personally identifiable information) are available from the corresponding author upon request.

\section{Consent for publication}

Not applicable.

\section{Competing interest}

The authors declare that they have no competing interests.

\section{Ethics approval and consent to participate}

The study reviewed by Animal Ethics and Experimentation review process of the Research and Community Services Council Office of the College of Veterinary Medicine, Gondar University, Ethiopia. Samples collected after getting verbal consent from willing owners. Considering the less invasive nature of the sampling procedure, verbal consent was enough and approved by the ethics review committee.

\section{Author's detailed}

Abiyot Workeale, Takusa district; livestock development agency office, Amahar region, Ethiopia. 
Samrawit Melkamu, College of Veterinary Medicine, Department of Veterinary Medicine, Samara University, Ethiopia.

\section{References}

1. Johnson SC, Treasurer JW, Bravo S, Nagasawa K, Kabata Z. A review of the impact of

2. parasitic Copepods on marine aquaculture. Zool. Stud. 2004; 43(2):229-243.

3. Kayis S, Ozcelep T, Capkin E, Altinok I. Protozoan and metazoan parasites of cultured fish in Turkey and their applied treatments. The Israeli J Aquac Bamidgeh.; 2009. 61:93-102.

4. Abdelhalim Al. Morphology and epidemiology of some parasitic monogeneans from British fresh water fish. PhD thesis, 1990; University of London,

5. Arafa SZ, El-Naggar MM, El-Abbassy SA. Mode of attachment and histopathological effects of Macrogyrodactylus clarii, a monogenean gill parasite of the catfish Clarias gariepinus, with a report on host response. Acta Parasitologica. 2009; 54:103-112.

6. Vinobaba P. Histopathological changes induced by ergasilidcopepod infections on the gills of food fish from Batticaloa lagoon, SriLanka, Sri Lanka. J. Aquat. Sci., 2007; 12: 77-87.

7. Rosety-Rodríguez, OM, Rosety FJ, Rosety, MJ. Carrasco,C. Morpho-histochemical changes in the gills of turbot, Scophthalmus maximus L., induced by sodium dodecyl sulfate. Ecotoxicology and Environmental Safety. 2002; 51:223-228.

8. Tuuha $\mathrm{H}$, Valtonen ET, and Taskinen J. Monogenea as parasites of Perch, Perca fluviatilis and roach Rutilus rutilus in Central Finland. Seasonality, maturity and environmental influence. Journal of Zoology., 1992; 128: 405-422.

9. Eissa IAM. Parasitic fish disease sin Egypt. Dar El- Nahda El- Arabia publishing, 2nd Edit. 23 Abd ElKhalak Tharwat St. Cairo, Egypt.2002.

10. Noor El-Deen, AIE. Comparative studies on the prevailing parasitic diseases in monosex tilapia and natural male tilapias in Kafr El Sheikh Governorate fish farms. Ph.D. thesis,Fac. Vet. Med., Kafr El Sheikh University.2007.

11. Mazon AF, Pinheiro GHD, Fernandes MN. Hematological and physiological changes induced by shortterm exposure to copper in the Freshwater fish Prochilodusscrofa.Brazilian JournalofBiology, 2003; $62(4): 621-631$.

12. Camargo MM, Martinez CB. Histopathology of gills, kidney and liver of a Neo tropical fish caged in an urban stream. Neotropical Ichthyology.2007; 5(3):327-336. I

13. Pritchard JB. The gill and homeostasis: transport under stress. The American Journal of PhysiologyRegulatory, Integrative and Comparative Physiology. 2003; 285 1269-1271.

14. Purivirojkul W. and Areechon, N. Asurvey of parasitic copepods in Marine fishes from Gulf of Thailand, Chon BuriProvince. J Natural Science. 2008; 42: 40-48.

15. Kurva R. and Gadadhar D. Department of Aquatic Animal Health,Faculty of Fishery Sciences, West Bengal University of Animal and Fishery Sciences 5, Budherhat Road, Chakgaria, Kolkata- 700094, 
2013; West Bengal, India..

16. Noga EJ. Text Book of diagnosis and" treatment Walworth" publishing, 1996; pp-92.U.S.A.

17. Ogundiran MA, Fawole SO, Ayandiran TA. Pathologic lesions in the gills of Clariasgariepinus exposed to sublethal concentrations of soap and detergent effluents. Animal Biology, 2009; 3(5): 078-082.

18. Roberts, RJ. Fish Pathology. Bailliere. Tindall. England. 2001; 477 pp.

19. Ostland VE, Ferguson HW, Stevenson RM. Case report, bacterial gill disease in goldfish Carrasiasa uratus Dis. aquat. Org. 1989; 6: 179-184.

20. Skelton P. A. Complete Guide to the Freshwater Fishes of Southern Africa, 2001; (p. 395). CapeTown: Struik Publishers.

\section{Figures}

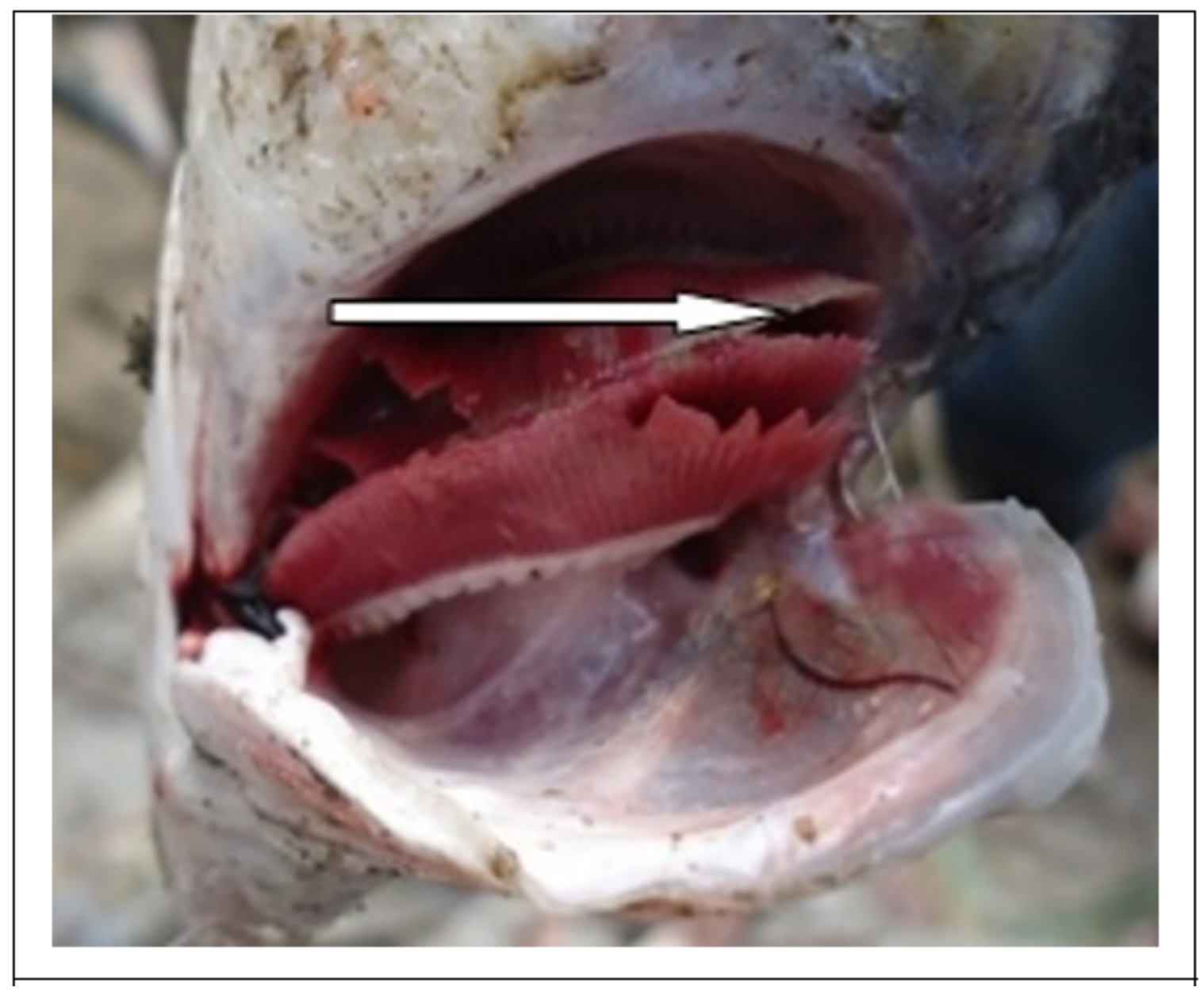

\section{Figure 1}

Palness of gill tissue 


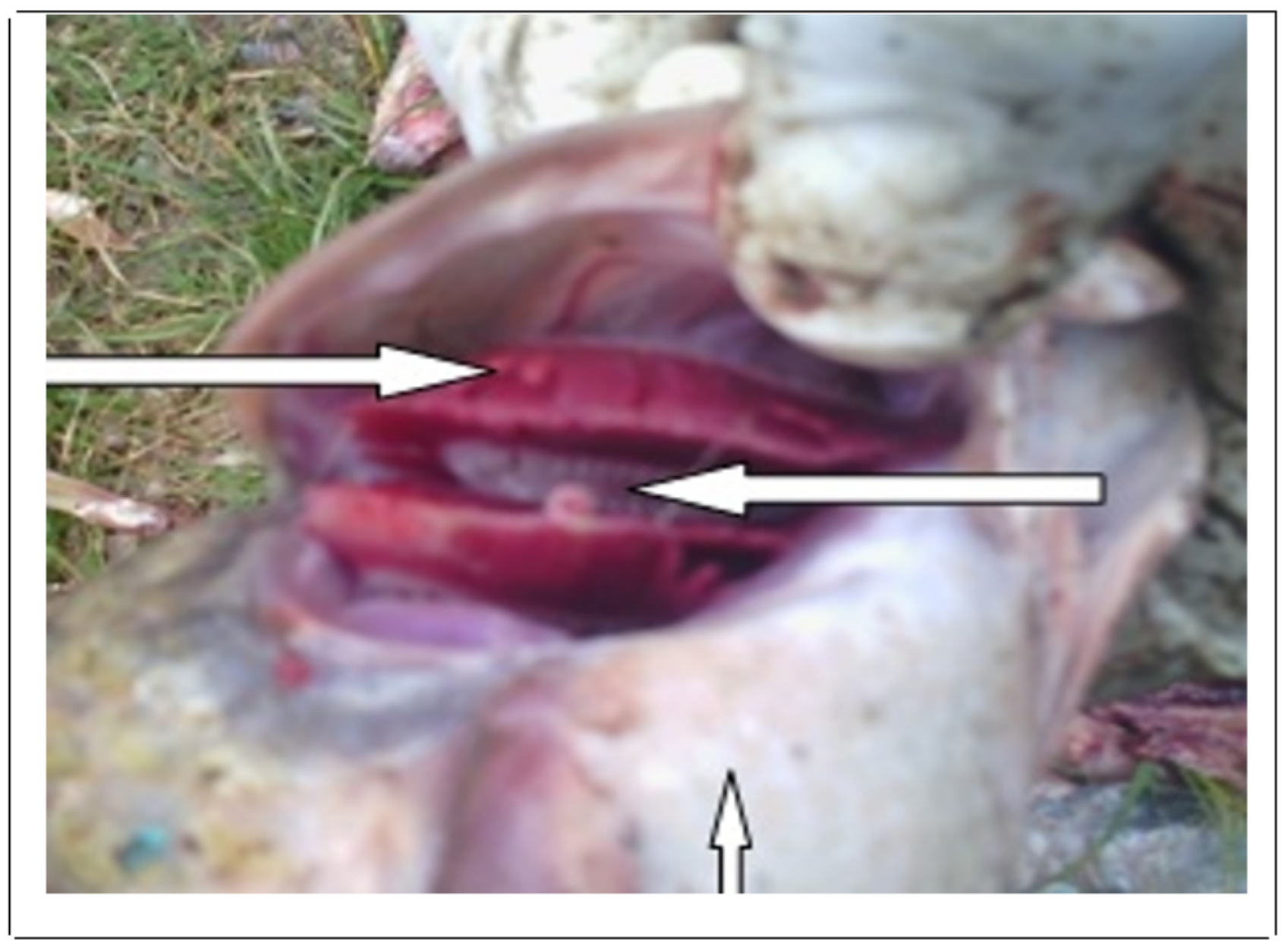

Figure 2

Monogenean parasite attached to the gills and congested 


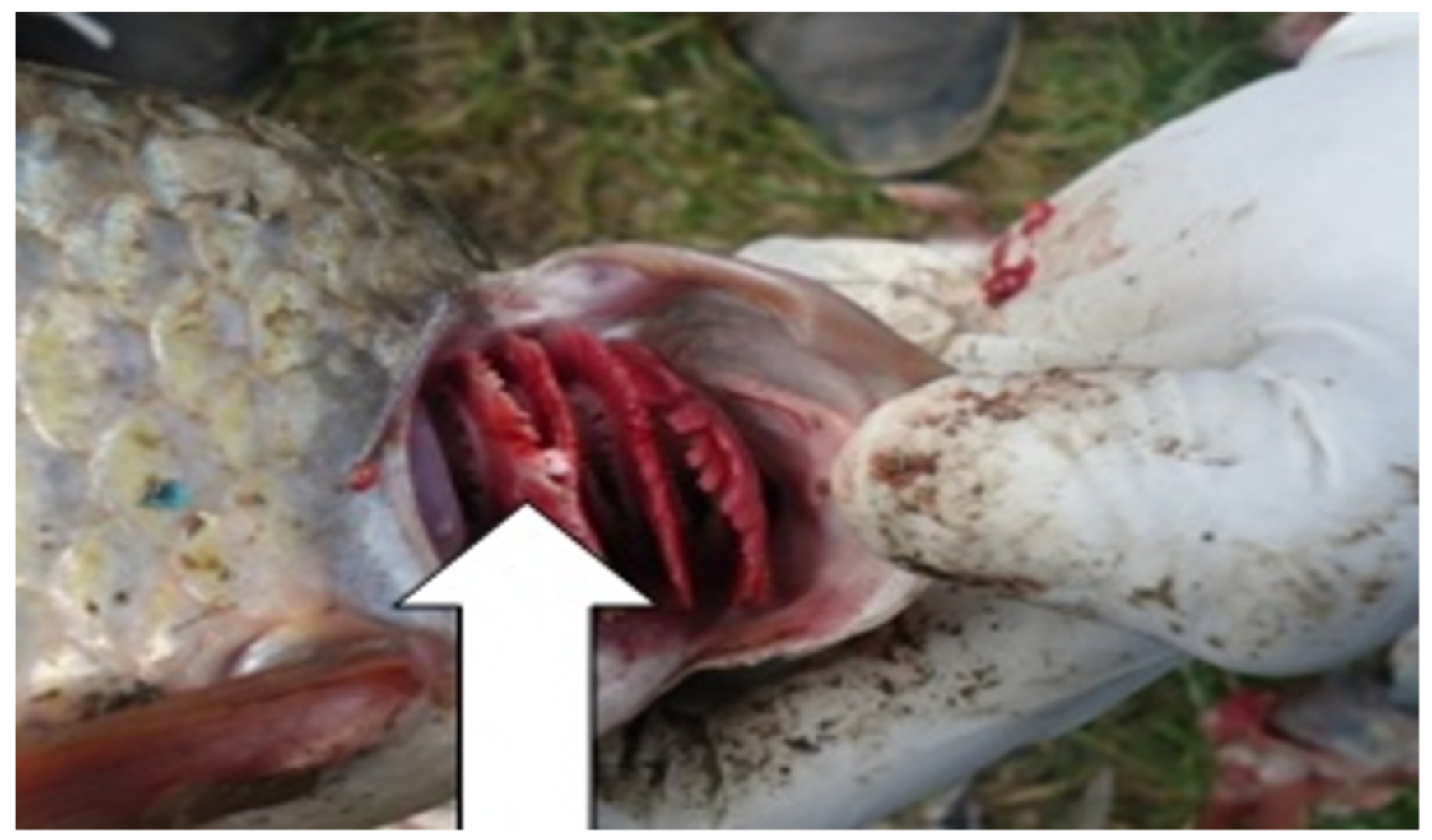

Figure 3

Monogenea parasite attached to between the gill filaments 


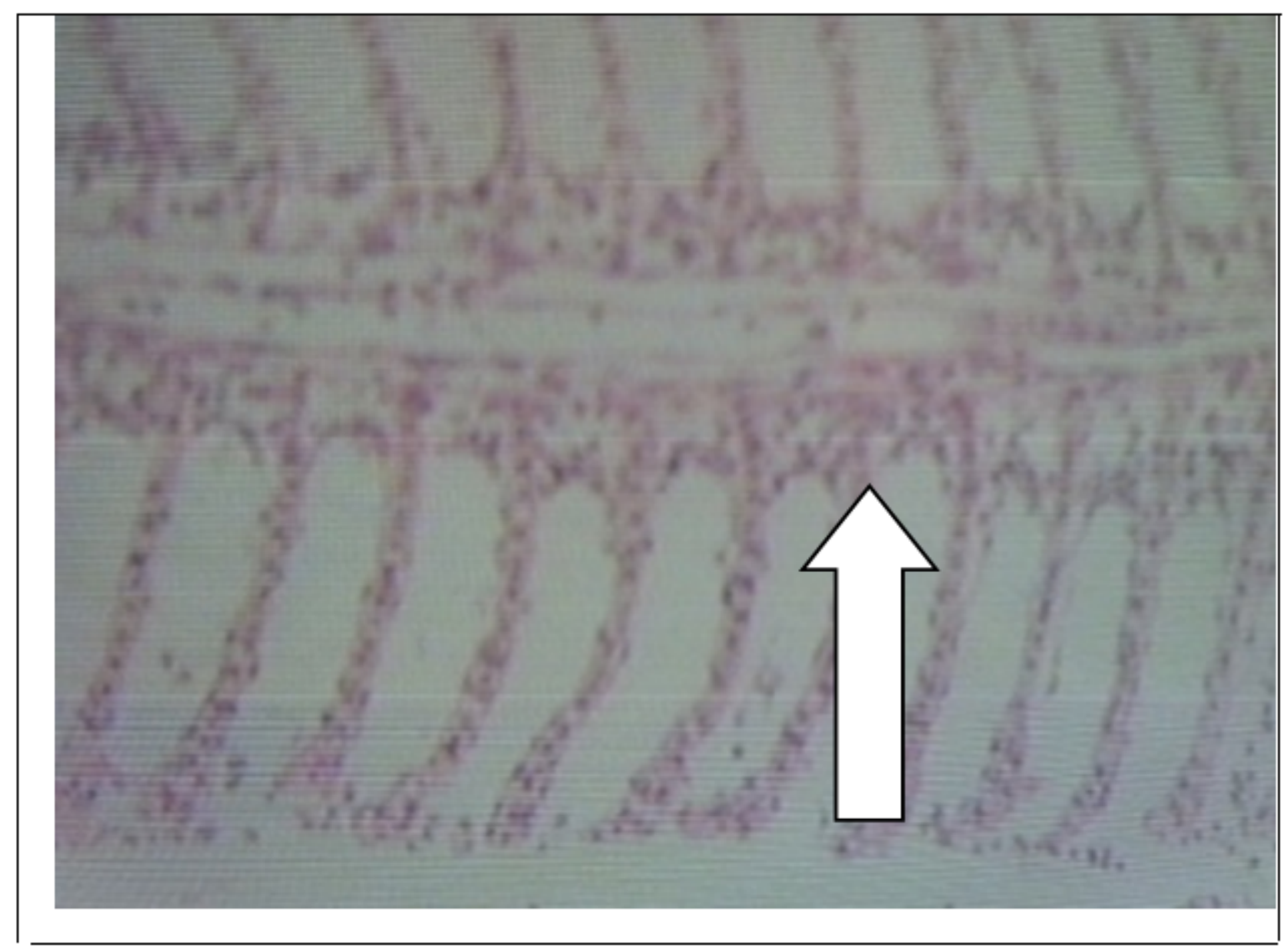

Figure 4

Normal structure of gills. 


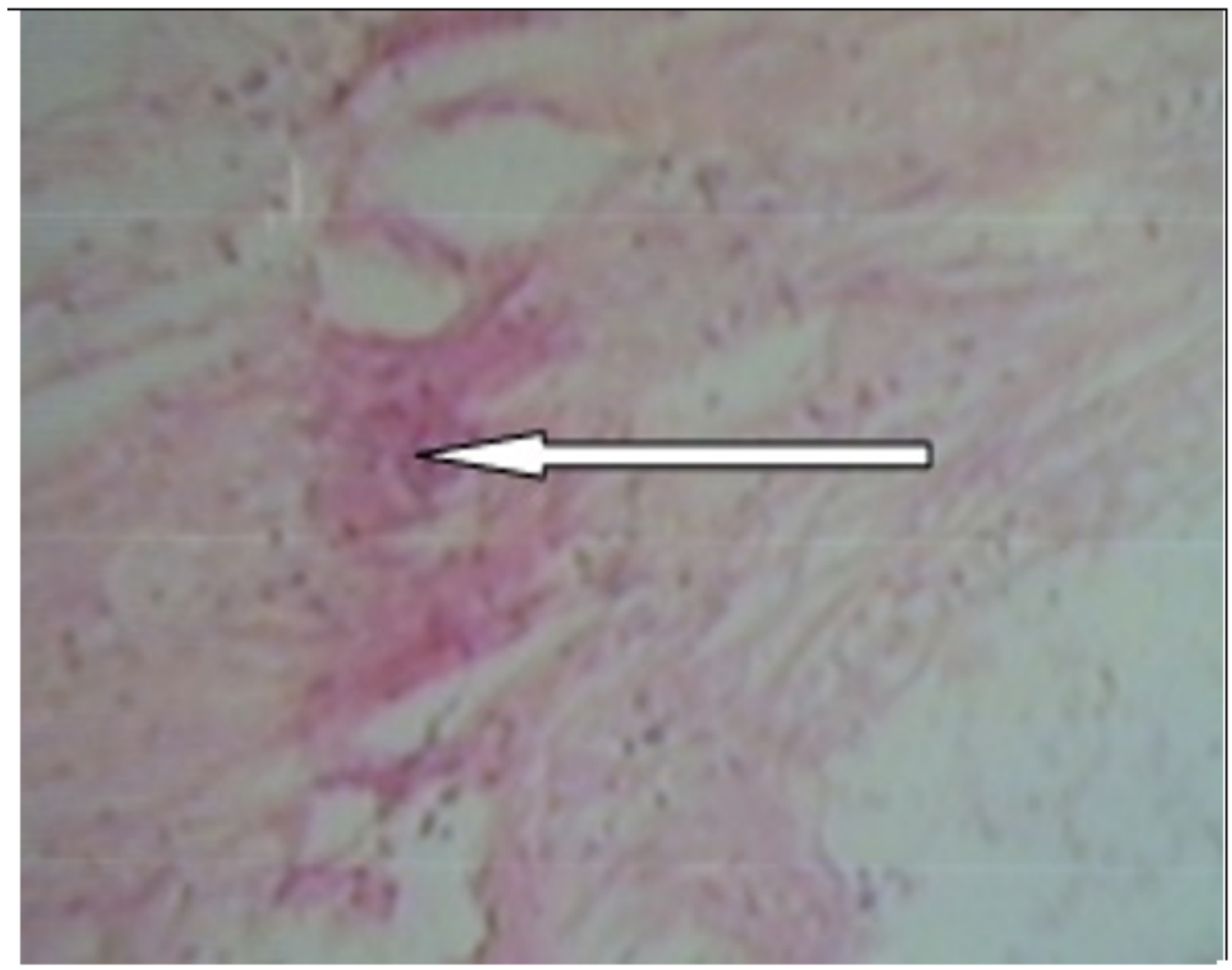

Figure 5

Hemorrhage of blood vessels 


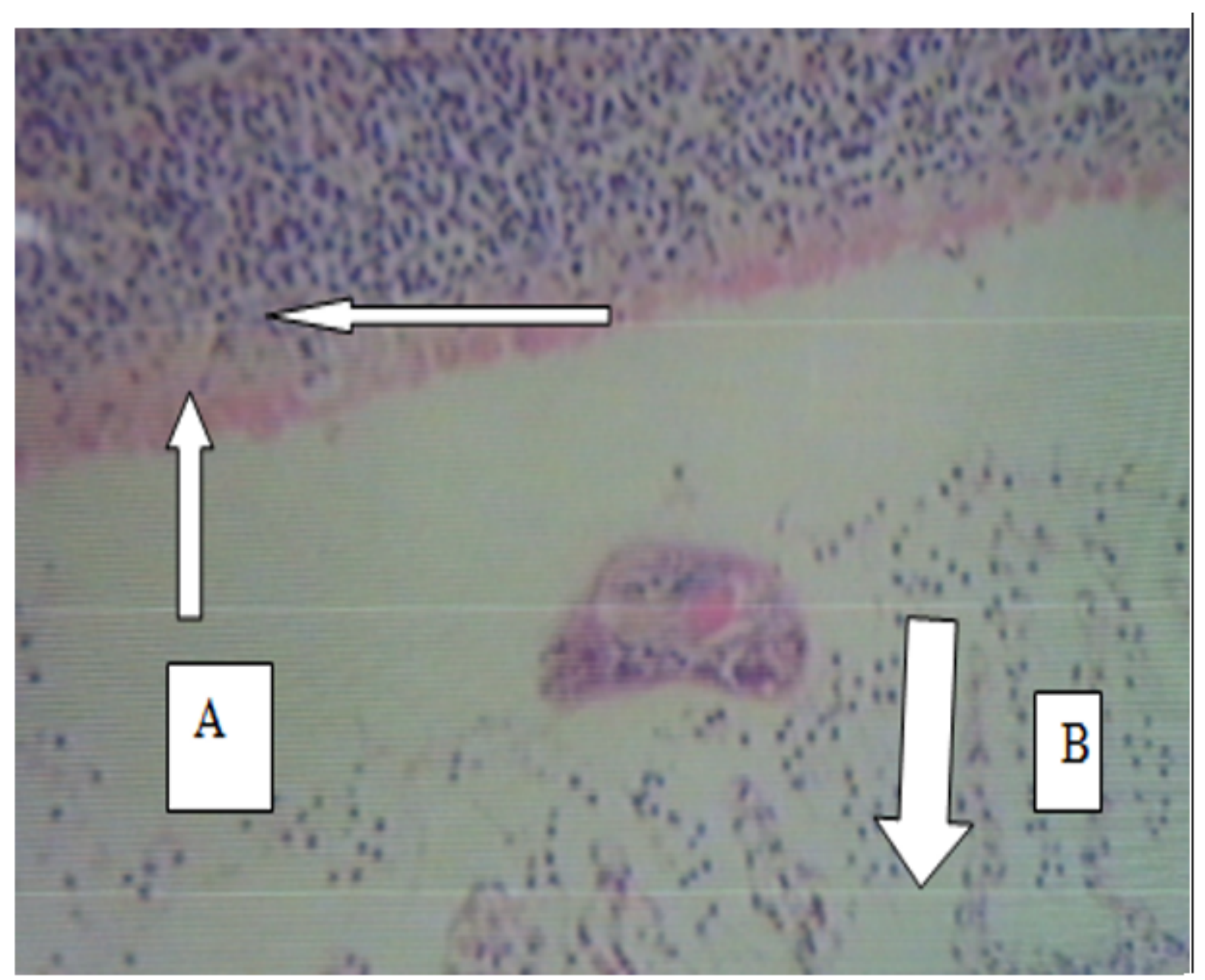

Figure 6

Monogenea parasite attached to the secondary gill lamellae(A) and chloride cell damage(B) (arrow 


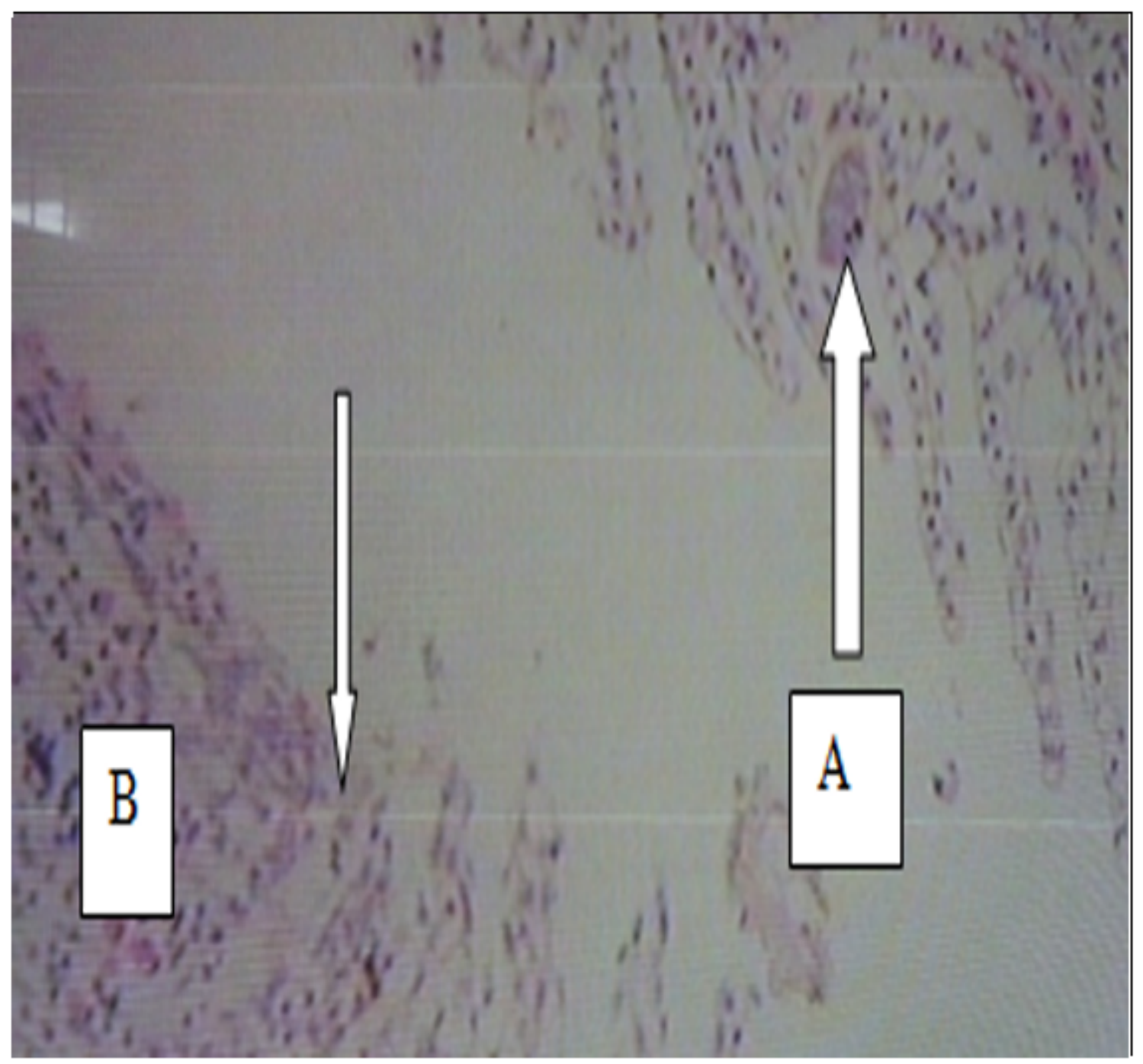

Figure 7

Monogenea parasite attached to inter lamellar space (a) and fusion of adjacent lamellae(B) (arrow) 


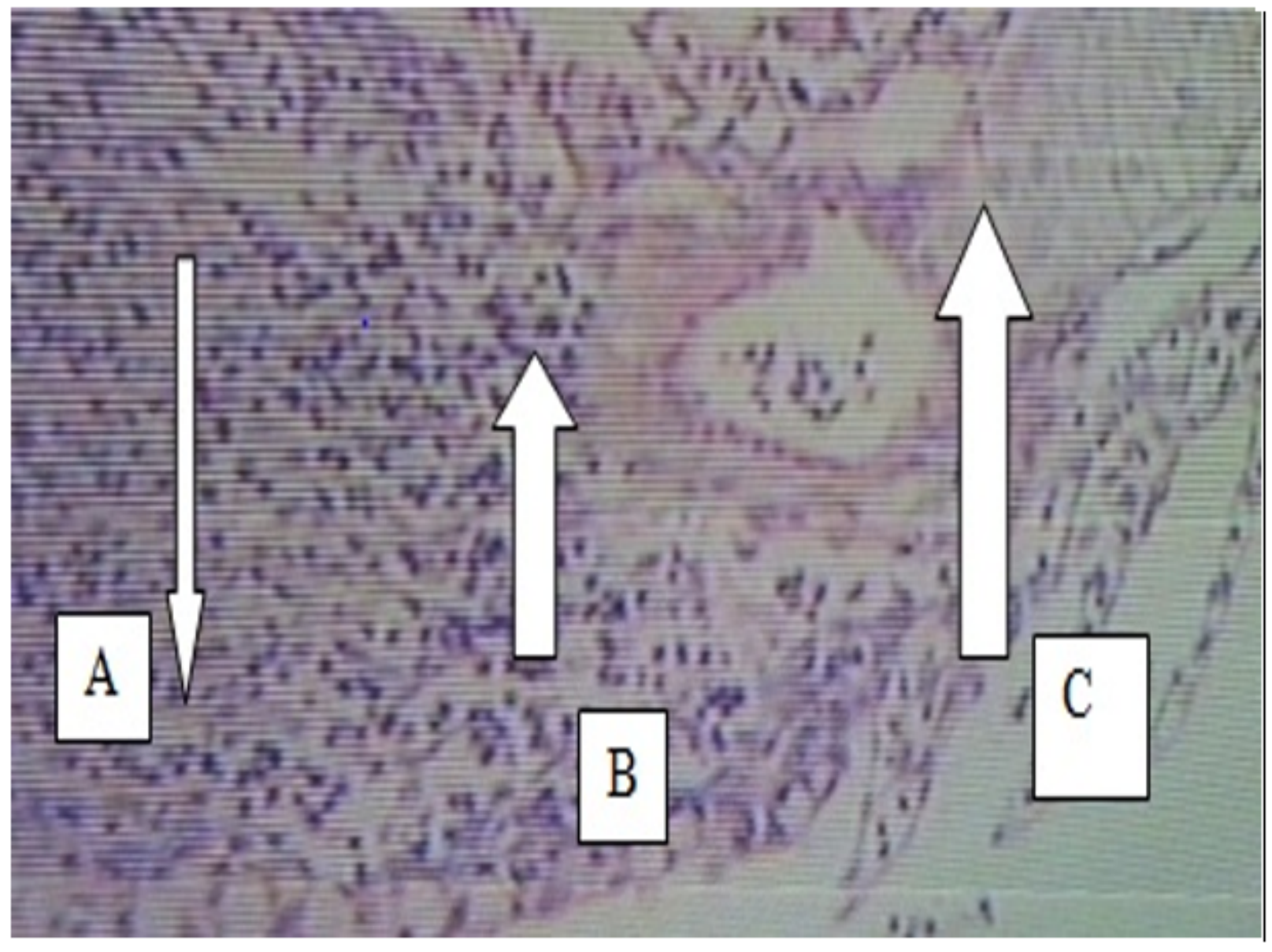

Figure 8

Increase number of goblet cell (A) leucocytes infiltration (B) congestion of blood vessel (C) (arrows) 


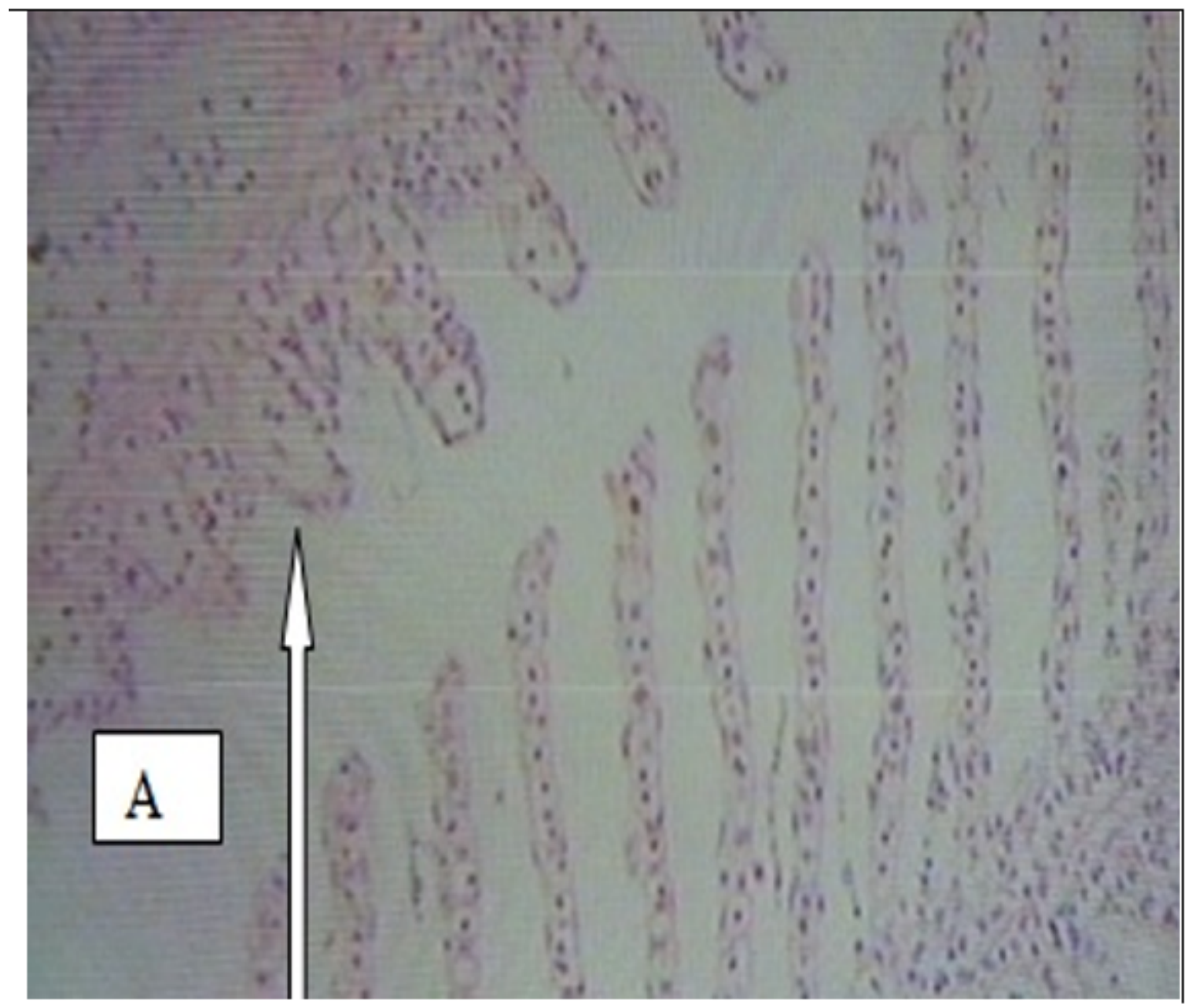

Figure 9

Atrophy of secondary lamellae (A) (arrow) 


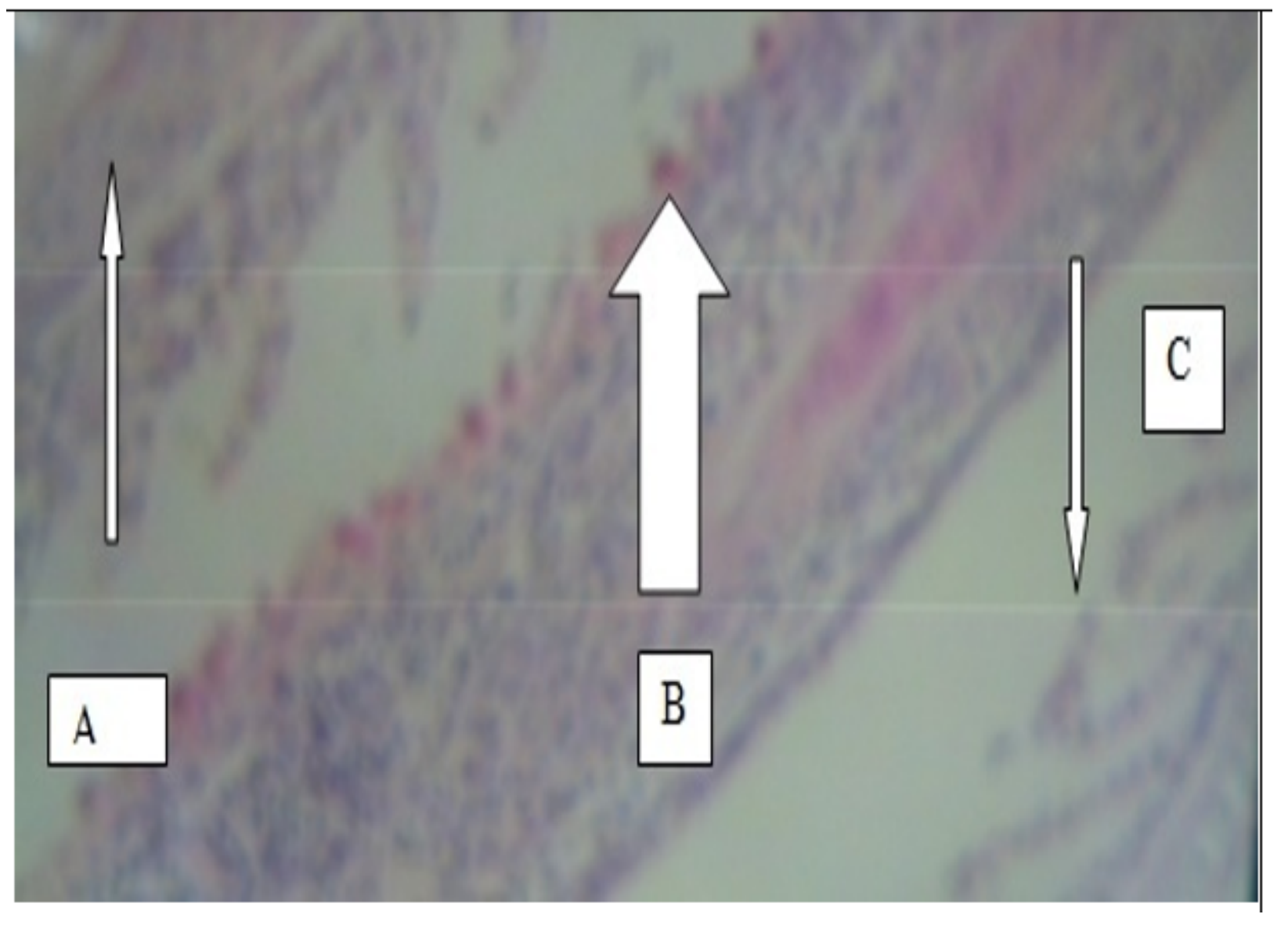

Figure 10

necrosis (A)complete loss of secondary lamellae(B)and decrease chloride cells number(C) (arrows) 


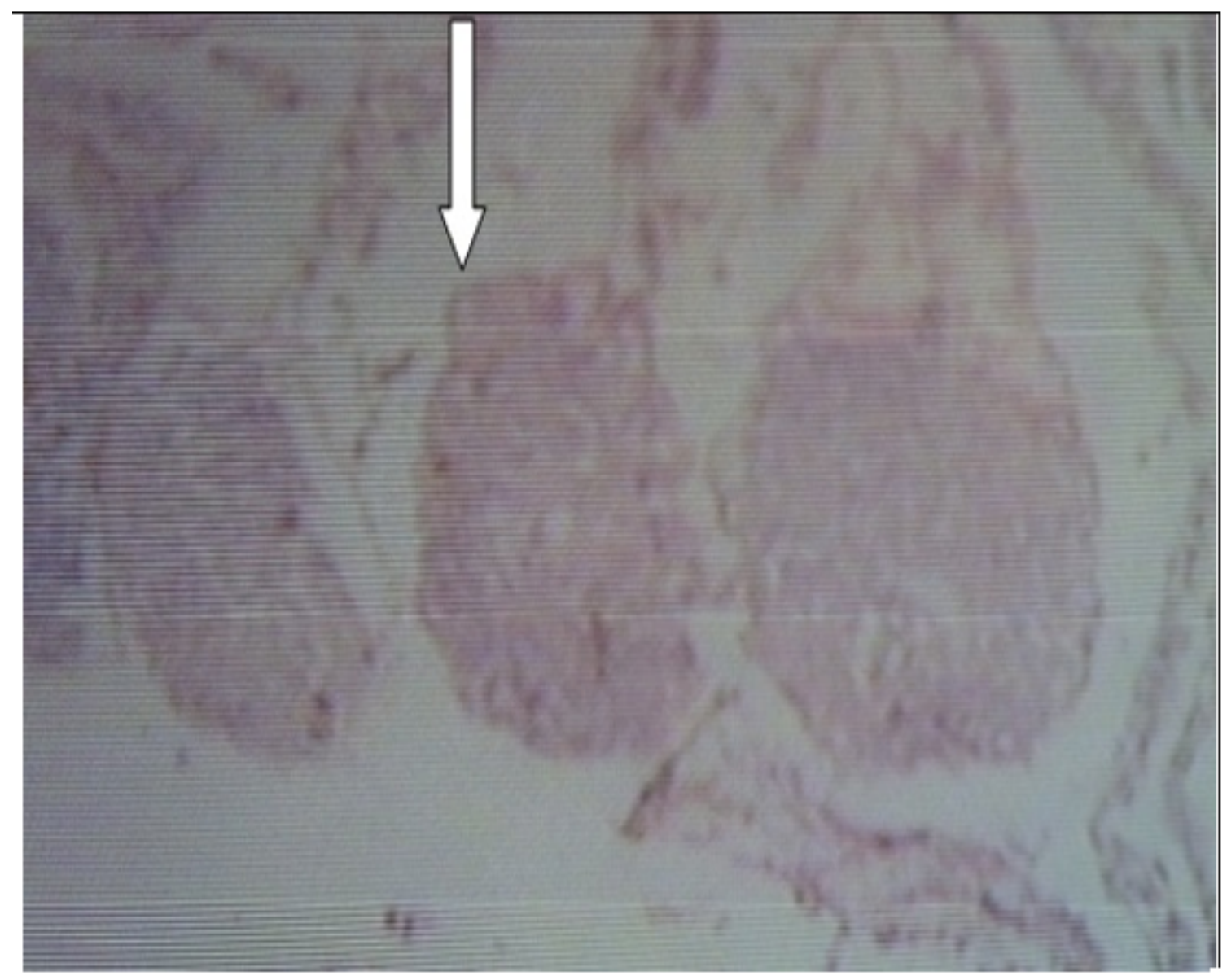

Figure 11

Telangiectasia condition at the tip of secondary lamellae (arrow) 